\title{
Defining the Burden of COVID-19 in the Kentuckiana Area: Incidence, Epidemiology, and Clinical Outcomes of Patients with COVID-19
}

\author{
Julio A. Ramirez ${ }^{1 A *}, M D ;$ Burden of COVID-19 Scientific Advisory Board ${ }^{B}$ \\ ${ }^{1}$ Division of Infectious Diseases and Center of Excellence for Research in Infectious Diseases (CERID), University of Louisville \\ APrincipal Investigator \\ BSee Appendix \\ *j.ramirez@louisville.edu
}

Recommended Citation: Ramirez JA. Defining the burden of COVID-19 in the Kentuckiana area: Incidence, epidemiology, and clinical outcomes of patients with COVID-19. Univ Louisville J Respir Infect 2020; 4(1):Article 4. doi: 10.18297/jri/vol4/iss1/4.

\begin{abstract}
Rationale: Early evaluation of the burden of disease that COVID-19 may produce in a community is critical to appropriately allocate resources for COVID-19 prevention and treatment.
\end{abstract}

Objective: The primary objective of this study is to define the incidence, epidemiology, and clinical outcomes of patients

\section{Background and Significance}

The World Health Organization (WHO) declared COVID-19 a pandemic on March 11, 2020.[1] The virus that causes COVID-19 is SARS-CoV-2. It is expected that SARS-CoV-2 will reach global spread and will infect a significant number of the global population. The declaration of a pandemic refers primarily to the capability of SARS-CoV-2 to spread from person to person at a global level, but the declaration of pandemic is not related to the severity of SARS-CoV-2. The burden of patients with COVID-19 may vary from region to region. This variability is primarily due to the mutations that SARS-CoV-2 will accumulate as the virus moves through the population. When the virus mutates, it undergoes small changes in its genome. A common pattern of evolution for viral infections is that as the virus mutates, it may have the capability to spread more efficiently from person to person, and at the same time, the strain may become less aggressive, which results in better outcomes in patients with the disease. Even though this is the most likely evolution of a virus, we do not know if the new mutations of SARS-CoV-2 will produce a virus more virulent or less virulent. At the present time, there are different patterns of burden of disease originating in China [2], Italy [3], and Germany with COVID-19 in the Louisville, Kentucky, and southern Indiana region (Kentuckiana) of the USA.

Methods: This will be a retrospective observational study of patients in the Kentuckiana region with the diagnosis of COVID-19.
[4]. Why the clinical outcomes of patients with COVID19 in these regions are different is unclear, but different viral mutations may partially explain the clinical outcomes.

Because of the above, it is clear that it will be difficult to predict the burden of COVID-19 in the city of Louisville, Kentucky and the surrounding area, regularly referred to as the Kentuckiana region, based on burden of disease from other regions. Defining burden of disease as soon as possible after SARS-CoV-2 arrives in the region is critical to properly inform public health authorities for development of effective preventive strategies, and healthcare professionals so they are able to appropriately and safely manage and treatment patients with COVID-19.

In an attempt to identify early burden of disease in Kentuckiana, the primary objective of this study is to define the incidence, epidemiology, and clinical outcomes of patients diagnosed with COVID-19 in Kentuckiana. 


\section{Objectives}

\section{Primary Objectives}

1. To define the incidence, epidemiology, and clinical outcomes of patients in Kentuckiana diagnosed with COVID-19.

\section{Secondary Objectives}

1. To evaluate incidence of COVID-19 in special populations.

2. To evaluate better inform Public Health authorities of local COVID-19 activity.

3. To define areas of the community where surveillance activities should be increased.

4. To rapidly disseminate the new knowledge gained by this project.

\section{Methods}

\section{Study Design and Subjects}

The Burden of COVID-19 study will be a retrospective cohort study of all patients in the Kentuckiana region with diagnosis of COVID-19, and has been approved by the University of Louisville Institutional Review Board as \#20-0257.

\section{Inclusion and Exclusion Criteria}

A patient will be defined as having COVID-19 when the virus SARS-CoV-2 was identified in a clinical specimen using Polymerase Chain Reaction (PCR). All patients with diagnosis of COVID-19 will be evaluated. The study will have no exclusion criteria.

\section{Incidence Calculations}

The monthly COVID-19 incidence rates per 100,000 adults will be estimated for: unique patients (unadjusted and age-adjusted), total hospitalizations, unique patients by various age groups, unique patients by comorbid conditions and smoking status, as well as for white and black/African American races.

\section{Geospatial Epidemiology}

To define specific hot areas with high density of COVID-19 in Kentuckiana, initially the geomasked location of each patient's home address will be obtained through the US Census Bureau website. A Kernel Density heatmap will be created. Kuldorff's Spatial Scan Statistic will be used to calculate significant areas of risk for COVID-19. Choropleth maps will be created to compare census tract-level demographics and the spatial distribution of COVID-19 cases.

\section{Mortality}

All-cause mortality for all COVID-19 patients will be evaluated at 30-days, 6-months, and 1-year after diagnosis. Mortality data will be obtained from the Kentucky Department for Public Health Office of Vital Statistics.

\section{Scientific Advisory Board}

A scientific advisory board has been established with leaders from Kentuckiana health care systems. The board has the following objectives: 1 ) To provide feedback for improvement of the Burden of COVID-19 study; 2) To support the dissemination of information. Regular meetings will be held by the principal investigator and members of the scientific advisory board.

\section{Preliminary Studies}

The principal investigator, Dr. Julio Ramirez, has vast experience in development and implementation of studies evaluating burden of particular infectious diseases.

Dr. Ramirez is the Chief of the Division of Infectious Diseases and Director of the Center of Excellence for Research in Infectious Diseases (ceridlouisville.org). He has led multiple surveillance programs in the State of Kentucky, including the Severe Influenza Pneumonia Surveillance (SIPS) Project. SIPS was funded by the Department of Homeland Security.[5] He was also funded by the Centers for Disease Control and Prevention to study the role of oseltamivir in hospitalized patients with influenza in the city of Louisville. This was done in collaboration of CERID with all adult hospitals in Louisville.[6] More recently, Pfizer Pharmaceuticals sponsored CERID to perform a population-based study of all hospitalized adult patients in the city of Louisville to define the burden of community-acquired pneumonia. Data from this study were used to estimate the burden of pneumonia in the United States.[7] The successes of these studies led to the selection of CERID as the North American Center of Excellence for Vaccine Epidemiology, funded by Pfizer. This is the first such center in the world, and recognizes the unique infrastructure and capabilities of UofL CERID (Center of Excellence annoucement).

\section{Project Coordinating Center}

The Burden of COVID-19 study will be coordinated by the Center of Excellence for Research in Infectious Diseases (CERID). The current structure of CERID is depicted in Figure 1. The activities related to this project for each of the CERID units are as follows: 


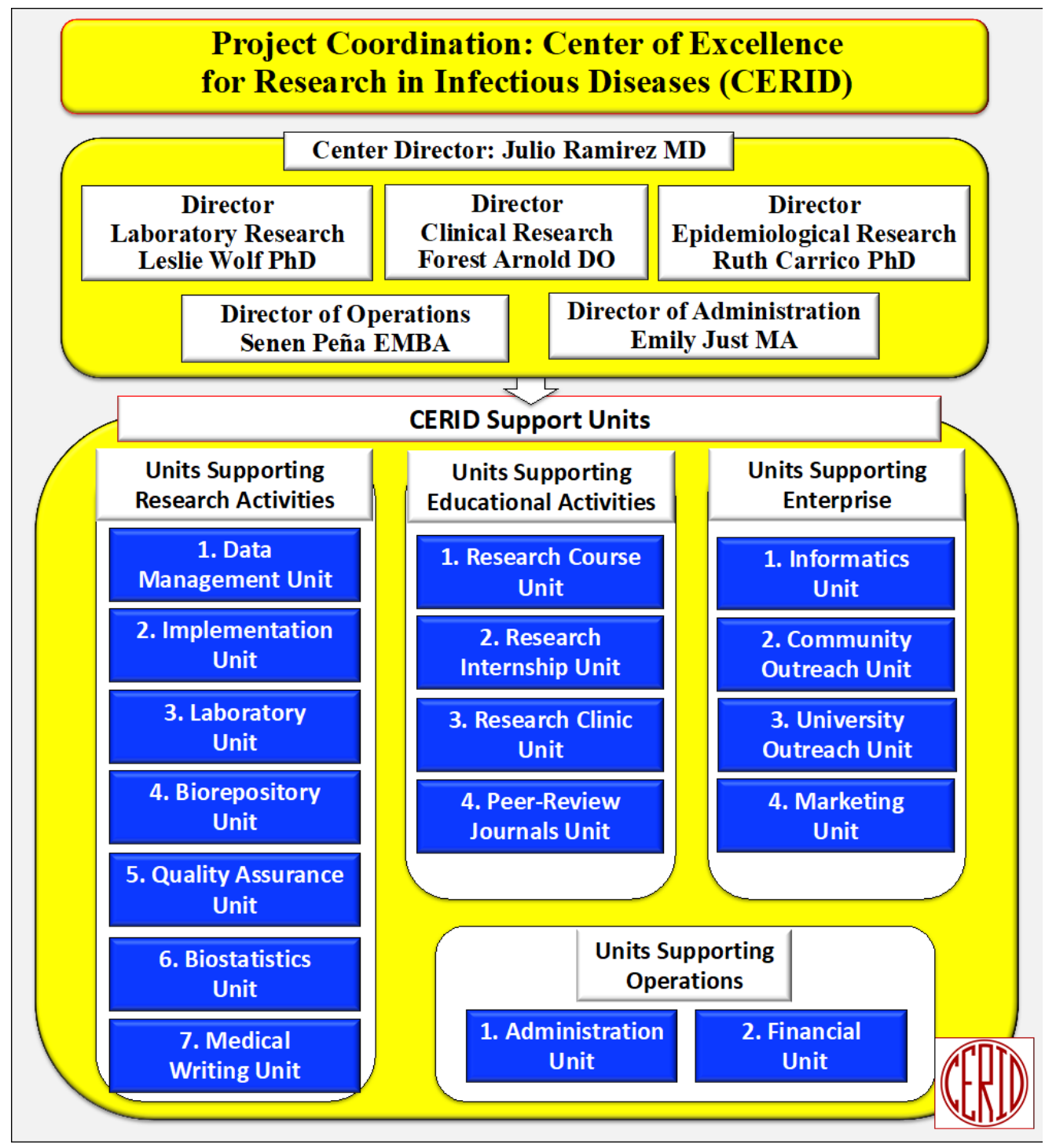

Figure 1. Structure of the project coordinating center.

Data Management Unit: generate the data collection form and the Research Electronic Data Capture (REDCap) database for this project.

Implementation Unit: responsible for data collection, and data entry into the REDCap database.

Laboratory Unit: no activity related to this retrospective study.

Biostatistics Unit: will be responsible for periodic and real-time analysis of incidence, epidemiological, and clinical outcomes data.

Medical Writing Unit: will support the generation of manuscripts.

Peer-Review Journals Unit: will facilitate rapid publication of new knowledge.
Informatics Unit: will support the data management unit and implementation unit in regard to computer and database maintenance.

Community Outreach Unit: will be responsible for maintaining open lines of communication with community leaders and coordinating activities of the Advisory Board.

University Outreach Unit: will be responsible for maintaining open lines of communication with UofL leaders and will work with the Community Outreach Unit to coordinate the activities of the Advisory Board.

Marketing Unit: will collaborate with investigators to develop education and response communications. 


\section{Protection of Human Subjects}

All patient information will be entered into REDCap databases, which are Health Insurance Portability and
Accountability Act (HIPAA)-compliant. All surveillance information is considered protected health information and standard data safety processes will be followed.
Published: March 31, 2020

Copyright: (c) 2022 The author(s). This original article is brought to you for free and open access by ThinkIR: The University of Louisville's Institutional Repository. For more information, please contact thinkir@louisville.edu. This article is distributed under the terms of the Creative Commons Attribution 4.0 International License (CC BY 4.0), which permits un- restricted use, distribution, and reproduction in any medium, provided the original author and source are credited.

Funding Source: The author(s) received no specific funding for this work.

Conflict of Interest: All authors declared no conflict of interest in relation to the main objective of this work.

\section{References}

1. World Health Organization. WHO Director-General's opening remarks at the media briefing on COVID-19 - 11 March 2020. Available at: https://www.who.int/directorgeneral/speeches/detail/who-director-general-s-openingremarks-at-the-media-briefing-on-covid-19---11-march2020. Accessed 11 March 2020.

2. Wang $D, H u B, H u C$, et al. Clinical characteristics of 138 hospitalized patients with 2019 novel coronavirus-infected pneumonia in Wuhan, China. JAMA 2020; 323(11):1061-9. doi: 10.1001/jama.2020.1585. PMID: 32031570.

3. Paterlini M. On the front lines of coronavirus: The Italian response to COVID-19. BMJ 2020; 368:m1065. doi: 10.1136/bmj.m1065. PMID: 32179517.

4. Rothe $C$, Schunk M, Sothmann $P$, et al. Transmission of 2019-nCoV infection from an asymptomatic contact in Germany. N Engl J Med 2020; 382(10):970-1. doi: 10.1056/NEJMc2001468. PMID: 32003551.
5. Wiemken T, Peyrani P, Bryant K, et al. Incidence of respiratory viruses in patients with community-acquired pneumonia admitted to the intensive care unit: Results from the Severe Influenza Pneumonia Surveillance (SIPS) project. Eur J Clin Microbiol Infect Dis 2013; 32(5):705-10. doi: 10.1007/s10096-012-1802-8. PMID: 23274861.

6. Ramirez J, Peyrani P, Wiemken T, Chaves SS, Fry AM. A randomized study evaluating the effectiveness of oseltamivir initiated at the time of hospital admission in adults hospitalized with influenza-associated lower respiratory tract infections. Clin Infect Dis 2018; 67(5):736-42. doi: 10.1093/cid/ciy163. PMID: 29659754.

7. Ramirez JA, Wiemken TL, Peyrani $P$, et al. Adults hospitalized with pneumonia in the United States: Incidence, epidemiology, and mortality. Clin Infect Dis 2017; 65(11):180612. doi: 10.1093/cid/cix647. PMID: 29020164. 


\section{Appendix: Burden of COVID-19 Scientific Advisory Board}

University of Louisville Center of Excellence for Research in Infectious Diseases

Ruth Carrico, PhD; Leslie Wolf, PhD

University of Louisville Center for Predictive Medicine

Kenneth E. Palmer PhD; Donghoon Chung, PhD

University of Louisville School of Public Health

William McKinney, MD

Louisville Public Health

Sarah Moyer, MD

University of Louisville Health

Jason Smith, MD; Forest W. Arnold, DO

Norton Healthcare Louisville

James Frazer, MD; Paul Schulz, MD; Ashley Wilde, PharmD

Baptist Health Louisville

Kenneth Anderson, MD; Anna Hart, MD

Clark Memorial Health

Klaus Boel, MD

Floyd Memorial Hospital

Krishna Konijeti, $M D$ 